\title{
1 Title: Laterally biased diffusion of males of the water flea Daphnia magna
}

2 Running title: Swimming behaviour of daphnids

3

4 Kenji Toyota $^{1,2,3 *}$, Masaki Yasugi ${ }^{4}$, Norihisa Tatarazako ${ }^{5}$, Taisen Iguchi ${ }^{6}$, Eiji Watanabe $^{7,8_{*}}$

$5{ }^{1}$ Marine Biological Station, Sado Center for Ecological Sustainability, Niigata University, Sado,

6 Niigata 952-2135, Japan.

$7{ }^{2}$ Department of Biological Sciences, Faculty of Science, Kanagawa University, Hiratsuka,

8 Kanagawa, Japan.

$9 \quad{ }^{3}$ Department of Biological Science and Technology, Faculty of Industrial Science and Technology,

10 Tokyo University of Science, Katsushika, Tokyo, Japan.

$11{ }^{4}$ Faculty of Engineering, Utsunomiya University, 7-1-2 Yoto, Utsunomiya, Tochigi 321-8585, Japan.

$12{ }^{5}$ Department of Science and Technology for Biological Resources and Environment, Graduate

13 School of Agriculture, Ehime University, Matsuyama, Ehime 790-8577, Japan.

$14{ }^{6}$ Graduate School of Nanobioscience, Yokohama City University, Yokohama, Kanagawa 236-0027,

15 Japan.

$16 \quad{ }^{7}$ Laboratory of Neurophysiology, National Institute for Basic Biology, Higashiyama 5-1,

17 Myodaiji-cho, Okazaki, Aichi 444-8787, Japan.

$18{ }^{8}$ Department of Basic Biology, Faculty of Life Science, SOKENDAI (Graduate University for

19 Advanced Studies), 5-1 Higashiyama, Myodaiji, Okazaki, Aichi 444-8787, Japan.

20

$21 *$ Correspondences and requests for materials should be addressed to K.T.

22 (toyotak@cc.niigata-u.ac.jp) and E.W. (eiji@nibb.ac.jp).

23

24 Key words (3-6 words): Daphnia magna, behaviour, sex difference. 


\section{Summary statements (15-30 words)}

2 We analysed the swimming behaviours of adult water flea Daphnia magna, and found apparent

3 sexual differences: laterally biased diffusion of males in contrast to the nondirectional diffusion of

4 females.

5

6

7 


\section{Abstract}

2 The water flea Daphnia magna is a representative example of zooplankton living in freshwater

3 environments. They primarily propagate via asexual reproduction under normal and healthy

4 environmental conditions. Environmental stimuli that signal a shift to disadvantageous conditions

$5 \quad$ induce D. magna to change their mode of reproduction from asexual to sexual reproduction. During

6 the sexual reproduction phase, they produce special tough eggs (resting eggs), which can survive

7 severe environmental conditions. Despite our increased understanding of their mating behaviours,

8 the sex-specific characteristics of swimming behaviours among daphnid species are poorly

9 understood. In this study, we analysed the swimming patterns and dynamics of female and male

10 adult D. magna. First, we found laterally biased diffusion of males in contrast to the homogeneous,

11 nondirectional diffusion of females. Second, computer modelling analysis using a discrete-time

12 Markov chain simulation, in which the frequencies of turning behaviour were evaluated as

13 probability distributions, explained the greater diffusion of males in the horizontal direction. Under

14 the presumption that high diffusion in the horizontal direction increases the probability of

15 encountering a distant mate, these findings led us to hypothesise that male D. magna increase

16 genotype heterogeneity by effectively selecting the probability distributions of certain motion

17 parameters. 
1

\section{Introduction}

For animals, survival depends on the ability to engage in appropriate behaviours in response to current circumstances. In various situations, animals must perform a range of behaviours, such as feeding, escape, aggression and sexual behaviours, by appropriately regulating their motor systems. Daphnids (referred to as water fleas), which are cladoceran crustaceans living in freshwater ecosystems, are no exception. Although they cannot perform smooth motion in the same manner as higher-order animals, such as humans, they can engage in appropriate behaviours to search for food, escape from predators and find mates using primitive sensors and motors (Ebert, 2005). In this study, we studied the swimming behaviours of Daphnia magna as a representative example of daphnid species (Figure 1). It is one of the most readily available and large species of daphnids, and it occupies a key position in food webs of shallow ponds.

The jumping-like motion of daphnids stems from the beating of their second antennae, which do not act as sensory organs but rather function in a manner similar to the oars of a boat (refer to supplemental movies 1 and 2). Their rapid downbeat produces a swift upward movement, whereas motionless organisms rapidly sink due to gravity (Haury and Weihs, 1976; Matsunaga and Watanabe, 2012). This rhythmic swimming pattern results in directed movement. In addition, these organisms occasionally drastically change their direction via irregular and disordered motion of their second antennae (Garcia et al., 2007). By simply repeating downbeats, succumbing to the pull of gravity and occasionally performing turning behaviour, they perform vertical and horizontal migration towards or away from a specific location in a pond or a lake. Such swimming patterns in a random fashion are widely observed in zooplankton species (Seuront and Strutton, 2003). Although these organisms freely move in water under constant conditions in the absence of specific physical stimuli, such as water flow or directional light, the motion of zooplankton is fundamentally explained by random walks or Levy flights (Bartumeus et al., 2003; Garcia et al., 2007; Kiørboe and Bagøien, 2005; 
1 Seuront et al., 2004a; 2004b; Visser and Thygesen, 2003), which are representative types of Markov as foraging (Bartumeus et al., 2003; Garcia et al., 2007). mating behaviours, such as encounters, grasping and copulation, have received growing attention (Brewer, 1998; Kerfoot, 1980; Winsor and Innes, 2002), given that daphnids have evolved a unique

11 reproductive system for increasing the encounter probability between female and male individuals in

12 a population. Their method of reproduction is termed cyclical parthenogenesis, in which

13 parthenogenetic (asexual) and sexual phases are interchanged in response to external environmental

14 stimuli, such as day length, temperature, nutrient availability and crowding (Banta and Brawn, 1929;

15 Hobæk and Larsson, 1990; Kleiven et al., 1992; Smith, 1915). Under favourable growth conditions, they parthenogenetically produce diploid eggs, giving rise to genetically identical female offspring. When environmental conditions deteriorate, they produce males and sexual females bearing haploid diapause eggs, permitting sexual reproduction and increasing genetic diversity. Resting eggs are resistant to harsh conditions, such as drying, freezing and exposure to the digestive enzymes of fish (Jarnagin et al., 2000). Despite this accumulated knowledge on daphnid mating behaviours, little information concerning sexual differences in swimming behaviours among daphnid species is available (Brewer, 1998). The goal of the present study was to elucidate the sex-specific swimming

23 patterns of adult daphnids and to reproduce these observed behavioural patterns via computer

24 modelling. We found laterally biased diffusion of males in contrast to the nondirectional diffusion of 
1 females. Computer simulation showed that the frequencies of turning behaviour are involved in

2 male-specific behaviour.

\section{$5 \quad$ Results}

\section{Overview of swimming patterns}

Figures $2 \mathrm{~A}$ and $2 \mathrm{~B}$ show the swimming trajectories of 28 female and 28 male D. magna individuals. They travelled on average $111.52 \pm 2.42 \mathrm{~mm}$ (females) and 96.17 $\pm 2.68 \mathrm{~mm}$ (males)

9 per individual from their starting position to their ending position in $8.53 \mathrm{~s}$ (256 frames), with mean

10 speeds of $13.07 \pm 0.028 \mathrm{~mm} / \mathrm{s}$ and $11.27 \pm 0.31 \mathrm{~mm} / \mathrm{s}$, respectively. In Figures $2 \mathrm{~A}$ and $2 \mathrm{~B}$,

11 consecutive coordinates were normalised to the given halfway point (the $129^{\text {th }}$ coordinate). To

12 reflect all data of the coordinates of the trajectory in a single graph, the trajectory graph was

13 transformed into a probability density plot (Figures 2C and 2D). Next, we performed kernel density

14 estimation. Whereas females exhibited a relatively symmetric distribution of movement in all

15 directions, males exhibited a biased movement distribution in the horizontal direction. The

16 horizontal-to-vertical ratio of high-density areas (density of 0.6 and greater; greenish yellow to white

17 in Figures 2C and 2D) was 1.35 in females and 2.10 in males. The highest density for females was

18 1.16-fold greater than that for males. Furthermore, a comparison of the area with a density of at least

19 the highest density for males (density of 1.1 and greater) revealed that the area for females was

20 4.29-fold larger than that for males.

\section{Mean squared displacement and autocorrelation function}

24 from the trajectories of D. magna females and males. The MSD was calculated independently in 
vertical and horizontal directions, and best-fit lines were calculated using a power-law square $=0.97)$ and 1.39 for males $(0.97)$. The power-law exponent in the horizontal direction was exponent was 0.88 in the vertical direction and 1.41 in the horizontal direction. The MSD plot of females moving in horizontal directions appears to consist of two time scales divided at approximately 5,000 ms (Figure 3, bottom, red). However, to compare diffusion rates of D. magna females and males, each of them was simply represented by a single power-law exponent. All power-law exponents larger than 1.0, indicating diffusion of both $D$. magna females and males, were

10 labelled as 'superdiffusion' in both directions. The motion analysis data also indicated that

11 horizontal diffusion rates of males were higher than those of females irrespective of the lower mean 12 speed of males.

14 function is shown in Figure 4. In both cases (for females and males as well as for vertical and

15 horizontal diffusions), distinct periodicity and autocorrelation characteristics were not observed. In many cases, a persistent random walk (or correlated random walk) was used for modelling the trajectories of the moving animals, given that the velocities of moving animals are persistent, in general (Codling et al., 2008). However, the present models include a fundamentally uncorrelated random walk because of the low autocorrelation characteristic. Using statistical MC models based on the discrete probability distributions of the velocities, move-step lengths, and SCISs (turns), we attempted to identify the parameter element contributing to the higher diffusion rate of $D$. magna

23 SCIS is a type of persistent random walk, given that the size values of SCIS are coupled with the

24 persistence of the movement direction. 
4 simulation was performed using the MC method. Computational results are shown in Figure 5. The

5 power-law exponent in the vertical direction was 1.43 for females (least mean square $=0.99$ ) and

61.17 for males (0.99) and that in the horizontal direction was 1.02 for females $(0.98)$ and 1.89 for

7 males (0.99). The male-to-female ratio of the power-law exponent was 0.82 in the vertical direction

8 and 1.85 in the horizontal direction.

10 Frequency of move-step length and MC2

11 The frequency distribution of the swimming speed (move-step length, $\mathrm{mm} / \mathrm{video}$ frame; $\mathrm{n}$

$12=7,168$ for each sex) is shown in Figure 6 . The results clearly illustrate a high frequency in the

13 lower move-step length, which gradually decreased as the move-step length increased. In both

14 female and male individuals, the frequency distributions were well fitted by exponential functions

15 (Figure 6, right). The slope of the regression lines for the vertical direction was -5.03 for females

16 (least mean square $=0.97$ ) and -6.08 for males $(0.99)$. The slope of the regression lines for the

17 horizontal direction was -4.55 for females $(0.98)$ and -5.59 for males $(0.96)$. For both directions, the

18 slope of the regression line was greater for females than for males. Significant differences in the

19 mean move-step lengths in each direction were observed between females and males (females and

20 males in the vertical direction: $0.26 \pm 0.0027 \mathrm{~mm} / \mathrm{video}$ frame and $0.21 \pm 0.0022 \mathrm{~mm} / \mathrm{video}$ frame,

21 respectively; and females and males in the horizontal direction: $0.28 \pm 0.0030 \mathrm{~mm} / \mathrm{video}$ frame and

$220.25 \pm 0.0027 \mathrm{~mm} /$ video frame, respectively; $p<0.05$, unpaired $t$-test). In both directions, the mean

23 move-step lengths of females were longer than those of males. 

power-law exponent in the vertical direction was 0.92 for females (least mean square $=0.98$ ) and the vertical direction and 1.06 in the horizontal direction.

\section{Size of a cluster with an identical sign and MC3}

In addition to regular jumping motions, D. magna occasionally makes a large change in

11 the direction of movement (left/right or up/down) via turning behaviour. These turning phenomena

12 can be represented by the direction of movement (left/right or up/down). We accordingly calculated

13 the sign of the direction of movement. Dominant and recessive directions were defined for each data

14 set, with the dominant direction represented by a plus sign (Figure 7A, see Methods for details).

15 Although the turning behaviours have a large effect on the global trajectory of D. magna, capturing the turning motion from local trajectories based on the time unit of the video frame is difficult. For this reason, to visualise the turning motion, we used a parameter termed SCIS, (Figure 7A, see

18 Methods for details). The frequency distribution of the parameter SCIS is shown in Figure 7B. A

19 long-tailed distribution (arrow) was found for positive-sign movements of males. In Figure 7C, the

20 dominant area of the frequency distribution is shown on logarithmic scales. The power-law exponent

21 of the frequency distribution in the vertical direction was -3.15 for females (least mean square $=$

220.98 ) and -3.12 for males (0.98). The power-law exponent in the horizontal direction was -3.22 for

23 females (0.96) and -1.87 for males (0.99). The mean distance in the horizontal direction was 118.84

$24 \pm 18.32 \mathrm{~mm}$ for males, significantly greater than that for females $(25.63 \pm 4.54 \mathrm{~mm})$. In contrast, the 
1 mean length of the movements of males in the vertical direction was $29.84 \pm 5.41 \mathrm{~mm}$, not

2 significantly different from that of females $(22.92 \pm 2.63 \mathrm{~mm})$. model 3 (MC3), which was derived from SCIS, were performed to calculate MSDs (Figure 8). The power-law exponent of the MSD in the vertical direction was 1.79 for females (least mean square = $0.98)$ and 1.82 for males $(0.99)$. The power-law exponent in the horizontal direction was 1.38 for females (0.98) and 1.96 for males (0.99). The male-to-female ratio of the power-law exponent was 1.02 and 1.42 in the vertical and horizontal directions, respectively. Characteristics of the two time scales observed in the motions of females in the horizontal direction (Figure 3, bottom, red) appear

10 to be reproduced by the MC3 model. The power-law exponents of the MSDs of $D$. magna and three

11 MC models are summarised in Table 1.

Table 1. Summary of three MC models.

\begin{tabular}{|c|c|cccc|}
\hline & & D. magna & MC1 & MC2 & MC3 \\
\hline \multirow{2}{*}{ Female } & $\mathbf{V}$ & 1.58 & 1.43 & 0.92 & 1.79 \\
& $\mathbf{H}$ & 1.29 & 1.02 & 1.07 & 1.38 \\
\hline Male & $\mathbf{V}$ & 1.39 & 1.17 & 0.92 & 1.82 \\
& $\mathbf{H}$ & 1.82 & 1.89 & 1.13 & 1.96 \\
\hline $\mathbf{M} / \mathbf{F}$ & $\mathbf{V}$ & 0.88 & 0.82 & 1.00 & 1.02 \\
& $\mathbf{H}$ & 1.41 & 1.85 & 1.06 & 1.42 \\
\hline
\end{tabular}

14 The power-law exponents of MSDs of D. magna and three MC models are summarised. V: vertical

15 direction, $\mathrm{H}$ : horizontal direction, $\mathrm{M} / \mathrm{F}$ : ratio of male divided by female. 
2 from D. magna, (2) MC1 and (3) MC3 (Figure 9B). NGDRs provide a measure of the relative

3 linearity of the swimming path of the plankton; lower NGDRs imply more curved trajectories. The NGDRs of the raw data from females were $0.32 \pm 0.027$ in the vertical and $0.32 \pm$

$5 \quad 0.050$ in the horizontal direction. The NGDRs of the raw data from males were $0.33 \pm 0.041$ and $0.70 \pm 0.053$ in the vertical and horizontal directions, respectively. The male-to-female ratios of the NGDRs were 1.03 in the vertical and 2.19 in the horizontal direction. These results indicate that NGDR in the horizontal direction for males was significantly higher than the other NGDRs $(p<$

90.01 , unpaired $t$-test). Thus, the linearity of the swimming path of males in the horizontal direction

10 was significantly greater than that of the other direction and sex.

11 This specificity was reproduced in the two MC models. The NGDRs of MC1 for females

12 were $0.13 \pm 0.015$ and $0.078 \pm 0.0087$ in the vertical and horizontal directions, respectively, and

13 those for males were $0.11 \pm 0.011$ and $0.54 \pm 0.013$, respectively. The male-to-female ratio of the

14 NGDR was 0.85 in the vertical and 6.92 in the horizontal direction. The NGDRs of MC3 for females

15 were $0.31 \pm 0.029$ and $0.28 \pm 0.030$ in the vertical and horizontal directions, respectively, and those

16 of males were $0.36 \pm 0.025$ and $0.77 \pm 0.025$, respectively. The male-to-female ratios of the NGDR

were 1.16 in the vertical and 2.75 in the horizontal direction. These results indicate that based on the MC models, the NGDR in the horizontal direction for males was distinctly higher than the other

NGDRs $(p<0.01$, unpaired $t$-test).

\section{Discussion}


1 calculated. All of these parameters showed that male adult D. magna individuals exhibit greater

2 diffusiveness in the horizontal direction than females. This male-dominant diffusion pattern was

3 computationally reproduced by the MC method in which the frequency map of the velocity was

4 considered as a probability distribution. Then, the factors that might have contributed to the

5 particularly high diffusiveness of males in random motions were analysed using the MC method.

6 The frequency maps of the migration length per unit time (absolute value of the moving velocity)

7 were nearly equal between females and males. The frequency distribution of the swimming speed in

8 females and males did not explain the higher diffusion of males in the horizontal direction. Because

9 these organisms often make drastic changes in the direction of movement, the frequency of turning

10 behaviour (SCIS) was calculated. When the frequency maps of SCIS were considered as a

11 probability distribution, the MC computational simulations reproduced the observed sexual

12 difference in diffusiveness, showing that male $D$. magna likely predominantly diffuse in the

13 horizontal direction by changing the frequency of turning behaviour. Regardless of the low

14 autocorrelation found for velocity, the sexual difference was reproduced in model MC3, which is a

15 type of persistent random walk. This result appears to show inconsistency. However, variation of move-step length was not included in MC3 (move-step length was constant in MC3). Considerable randomness and variation of move-step length may have contributed to the low autocorrelation.

18 Furthermore, two-valued directions (plus or minus) in SCIS possibly enhance the persistency. In

19 either case, it should be noted that SCIS analysis extracts the persistency from low-autocorrelation data. For detailed evaluation of this question, comparison with other analyses using data with higher spatial and temporal resolution or data to which a smoothing method applies will be helpful (Hen et al., 2004; Postlethwaite and Dennis, 2013). 
1 processes. Nonetheless, all of these indices commonly captured the greater diffusiveness of males in

2 the horizontal direction. Such preferred movement by males in the horizontal direction has been

3 observed in another daphnid species (D. pulicaria) (Brewer, 1998). Females exhibited a strong

4 vertical swimming component, ranging from -60 to +75 from the horizontal, whereas male

$5 \quad$ swimming behaviour was primarily linear and horizontally oriented, with swimming angles

6 deviating no more than \pm 15 from the horizontal. Furthermore, very different motility was observed

7 between female and male copepod crustaceans (Centropages typicus and Pseudocalanus elongates)

8 (Kiørboe and Bagøien, 2005). Males were more directionally persistent than females based on

9 root-mean-square net distance. Thus, the comparatively high diffusion of males in the horizontal

10 direction may be a general phenomenon in zooplankton. Over 200 species of daphnids (Kotov et al.,

11 2012) and over 13,000 species of copepods (Boxshall and Defaye, 2008) have been discovered to

12 date; however, there are few zooplankton in which motion patterns have been investigated. Further

13 verification of their behaviour is required.

14

Random motion of D. magna

In this study, we investigated the autonomous movement pattern of D. magna individuals

under uniform conditions with no water stream, a constant light cycle and temperature. To avoid 
2 raw tracking data considered as a probability distribution. As a result, the differences between males

3 and females mentioned above were reproduced. Thus, it can be inferred that it is appropriate to

4 analyse as a Markov process the difference in diffusion between males and females. Reproducibility

5 using the MC model indicates that only the present position is used as past information determining

6 the future motion of plankton and that the future motion follows specific probability distributions. In

7 our recent study, when visual stimulation was generated via a MC method in which speed

8 distribution data from raw tracking data of female D. magna were considered as a probability

9 distribution, visual stimuli promoted the feeding behaviour of medaka fish (Oryzias latipes)

10 (Matsunaga and Watanabe, 2012). This finding suggests that the Markov process observed in the

11 movement of D. magna is an important biological phenomenon. Furthermore, in this study,

12 movement of D. magna was separated into migration distance per unit time and frequency of turning

13 behaviour. The frequency of turning qualitatively explained the behaviour of males.

14 Turning behaviour has been observed in small organisms such as Caenorhabditis elegans

15 (Ohkubo et al., 2010; Srivastava et al., 2009), Paramecium (Nakaoka et al., 2009) and Drosophila

16 (Censi et al., 2013). These turning behaviours occur even under spatially and temporally uniform

17 conditions, indicating that these are self-motivated and voluntary behaviours. Theoretical studies

18 suggest that stochastic behaviours are important for efficiently searching for prey and mates

19 (Bartumeus et al., 2008). A similar turning phenomenon was observed in feeding female D. magna,

20 phytoplankton distributed throughout the aquatic systems of lakes and ponds. The male D. magna

21 could have adapted to the rapidly changing habitat environment by slightly reducing their probability

22 of turning. To clarify the biological meaning of this stochastic process, the presence of some internal

23 mechanism regulating the probability distribution of turning behaviour is suggested. 
2 sex-specific behavioural differences. Indeed, mature male daphnids are distinguishable from females

3 not only by their testes and sperm but also by several apparently distinctive morphological

4 characteristics, such as a smaller body size, elongated first antennae and a copulatory hook at the

5 first thoracic leg (Brewer, 1998; Mitchell, 2001). However, the causal relationships of the sexual

6 differences between behavioural and morphological characteristics in daphnid species remain largely

7 unknown.

$9 \quad$ Acquisition of genetic heterogeneity

10 As mentioned above, the higher diffusiveness of male zooplankton has been observed in

11 multiple species, and the underlying dynamic regulation of turning has been reported in various

12 animal species (Censi et al., 2013; Nakaoka et al., 2009; Srivastava et al., 2009). Thus, discussing

13 the biological significance of this difference in diffusiveness would be useful, even though a

14 conclusion on this issue is beyond the scope of the present study. Here we propose simply that the

15 high diffusiveness of male D. magna is closely related to ensuring genotype heterogeneity.

As shown in Figure 2C, female D. magna exhibit heavier recursiveness to the point of

origin, indicating that the motion of females exhibits less diffusion than that of males. Under normal 
1 eggs that exhibit high genetic variation. It appears reasonable that water fleas living in shallow ponds

2

concentrate their energy in horizontal directions.

Traditionally, behavioural patterns of daphnids have been demonstrated by population (mass culture) levels under laboratory and/or natural environments (Beaver et al., 2018; Dodson, 1988). Recent technologies have enabled the individual-level behavioural analysis by tracking video system, and it can be applied for the toxicological and risk assessment of chemicals as a novel endpoint (e.g., swimming velocity and trajectory) in addition to, for examples, survival rate and fecundity of D. magna (Bownik et al., 2019; 2020; Felice et al., 2019; Noss e al., 2013). Although D. magna has been used in ecotoxicological studies as a representative surveillance organism to monitor changes in water quality (Martins et al., 2007), little is known about the basic mechanisms involved in its behaviour. In this study, we found that male individuals travelled in a diffuse horizontal direction relative to females. Furthermore, this male-specific diffusion pattern was reproduced by mathematical modelling using MC simulation, in which a frequency map of their turning behaviour was used as a probability distribution. Although it is necessary to clarify strain differences of behavioural patterns (Oda et al., 2007), current data provides an insight of new endpoints to OECD Test Guidelines no. 211 using daphnids (OECD, 2012), enabling the validation of chemical toxicity based on behaviour. Likewise, we recently found useful Daphnia strains that can produce female or male in response to day-length differences in the D. pulex (Toyota et al., 2015) and D. magna (Toyota et al., 2019; 2021). These strains will be used for comparative behavioural analysis of inter- and intra-species between sexes, and moreover 3D tracking approaches (Bianco et al., 2013) will shed light on the well-conserved innate behavioural patterns of daphnids. Our findings provide the first insight into the behavioural characteristics of female and male adult $D$. magna individuals and lay the foundation for advancing our understanding of the dynamics of daphnid populations and the toxic effect of chemicals released into the aquatic environment. 


\section{$3 \quad$ Materials and Methods}

\section{Daphnia magna strain and rearing conditions}

A D. magna strain (Belgium clone) was obtained from the National Institute for

6 Environmental Studies (NIES; Tsukuba, Japan) (Oda et al., 2006). Stock populations were

$9 \mathrm{~h}$ light/dark cycle (with lights on from 08:00 to 22:00). The housing water was prepared by mixing

10 artificial sea salt into deionised $\mathrm{H}_{2} \mathrm{O}(18 \mathrm{~g} / 60 \mathrm{~L}$; Tetra Marine Salt Pro, Tetra Japan, Tokyo, Japan)

11 (Matsunaga and Watanabe, 2012). A chlorella (Chlorella vulgaris) suspension ( $0.3 \mathrm{~mL} / 10 \mathrm{~L}$;

12 Chlorella Industry, Tokyo, Japan) was added to the housing tank as a food source once a day at

13 08:30. This strain occasionally produces male offspring in addition to female offspring under

14 overpopulation conditions. Male juveniles were easily distinguished based on their elongated first

15 antennae (Olmstead and LeBlanc, 2000). Two- to three-week-old male and female animals were used in subsequent experiments.

Motion recording 
covered with black rubber to prevent excessive illumination and light reflection. The test tank was

Video images $(640 \times 480$ pixels $)$ were recorded at 30 frames per second $(\mathrm{fps})$ and were quantified with DIPP-Motion 2D motion analysis software (DITECT, Tokyo, Japan). The coordinates of the centre of mass of the individuals were automatically tracked in each video frame. The coordinates were obtained as integer numbers (horizontal coordinates from 0 to 639; vertical coordinates from 0 to 479). Three or four D. magna individuals were tracked in each experiment. Data points in which individuals collided against each other or the tank walls were excluded. Thus, sexual differences in swimming behaviours were studied in reference to the autonomous movement pattern of each

14 individual in a uniform environment. Consecutive coordinates (257) for each daphnid were treated as

15 a data set, and 28 data sets were collected for each sex. The frequency distribution of the velocities showed a single peak with wide tails located at either side (Supplemental Figure 1). The maximum values were 13 pixels (horizontal) and 13 pixels (vertical) for females and 9 pixels (horizontal) and 10 pixels (vertical) for males. The minimal values were -14 pixels (horizontal) and -14 pixels (vertical) for females and -12 pixels (horizontal) and -9 pixels (vertical) for males. In the following analysis, these integral data were used and then finally converted to millimetre scale.

\section{Kernel density estimation}

In total, 7,196 coordinates (240 sets, 257 consecutive coordinates per individual D. magna,

$24 n=28$ for each sex) of the calculated centre of mass of D. magna were obtained. The consecutive 
1 coordinates were normalised to the given halfway point (the $129^{\text {th }}$ coordinate), which was set as

2 vertical coordinate 50 and horizontal coordinate 50 (Figure 1, top). Nonparametric kernel density

3 estimation (Silverman, 1986; Fortmann-Roe et al., 2012; Worton, 2002) of the normalised trajectory

4 data was performed using a quartic kernel function with a bandwidth of $12 \mathrm{~mm}$. The kernel density

$5 \quad$ estimator at coordinate $\mathbf{x}$ is given as follows:

$6 \hat{f}_{h}(\mathbf{x})=\sum_{d_{i} \leq h} \frac{3}{\pi h^{2}}\left(1-\frac{d_{i}^{2}}{h^{2}}\right)^{2}$,

$7 \quad$ where $h$ is a smoothing parameter termed bandwidth and $d_{i}$ is the distance from coordinate $\mathbf{x}$ to coordinate $\mathbf{x} i$. The kernel density estimator was applied to $12,100(110$ vertical $\times 110$ horizontal $)$ coordinates and the two-dimensional density map was visualised with terra colours using R software (http://www.r-project.org/).

\section{Motion analysis}

$$
\operatorname{MSD} \equiv\left\langle\left(\mathbf{x}(t)-\mathbf{x}_{0}\right)^{2}\right\rangle
$$

$t$.

The discrete autocorrelation Rs at lag $n$ were computed as follows:

$$
\mathrm{R}(n)=\frac{1}{N} \sum_{t=0}^{N-1} v(t) v(t+n)
$$

22 where $v(t)$ is the velocity of an individual plankter at a specific time $t$. The normalised autocorrelation function (ACF) was calculated as follows: 


$$
\operatorname{ACF}(n)=\frac{R(n)}{R(0)}
$$

Net-to-gross displacement ratios (NGDRs) (Figure 9) were computed as follows (Busley,

$$
\mathrm{NGDR} \equiv \frac{\mathrm{ND}}{\mathrm{GD}}
$$

3 where ND (mm) and GD ( $\mathrm{mm})$ are the net and gross displacements, respectively, of an individual;

4 these measures correspond to the shortest distance between the starting and ending points of the

$5 \quad$ trajectory and the actual distance travelled by an individual, respectively. NGDRs were computed at

6 the finest available resolution (1/30 s) for each track. The statistical significance of the results of

$7 \quad$ NGDR was determined using unpaired (two-tailed) $t$-tests. The threshold for statistical significance was $p<0.05$. Values are reported as means \pm SEM.

10 most frequent sign was defined as the dominant direction. Dominant and recessive directions were

11 determined for each set of data, and the dominant direction was represented anew by a plus sign. The

12 movement distance per frame was converted to values accompanied by signs referring to the

13 dominant and recessive directions. The size of a cluster with an identical sign (SCIS) was calculated

14 as the duration for which identical signs were continuous (Figure 7A). Periods of zero speed were

15 assigned the sign of the preceding period.

Markov chain simulation 
1 generated by a randomiser referencing the discrete probability distributions of velocities (model

2 MC1), move-step lengths (model MC2) or SCISs (model MC3). Then, we defined

3

4

$$
x_{0}=0, x_{n}=\sum_{j}^{n} x_{j},
$$

where $x_{0}$ is the initial position of a model plankter and $x_{n}$ is the position of the individual at a discrete specific time j. Finally, the MSDs and NGDRs of each set of progressions $\left\{x_{n}\right\}$ were calculated. Progressions $\left\{v_{1}, v_{2}, v_{3}, \ldots, v_{255}\right\}$ for each MC model were generated as follows. MC1. 1) The raw velocity data from $28 \mathrm{D}$. magna individuals were collected into a data set (255 velocities per individual; $n=7,140$ in total for each direction). 2 ) In total, 255 values were randomly selected from each data set. The values were selected with repetitions. 3) A random selection of values was repeated 28 times for each data set. The reselection of an identical data point was not excluded.

MC2. 1) The raw move-step length data from 28 D. magna individuals were collected into a data set. 2) In total, 255 values were randomly selected from each data set. 3) A random selection of values was repeated 28 times for each data set. Values were selected with repetitions. 4) A plus or minus sign was randomly assigned to the selected move-step length.

MC3. 1) The raw SCIS cluster data from 28 D. magna individuals were collected into a data set. Each cluster included a sign (plus or minus) and a discrete size. 2) A cluster was randomly selected from each data set. 3) The selected cluster was converted to a progression where 1 (if the cluster sign was plus) or -1 (if the cluster sign was minus) was sequenced by the length of the cluster size. 4) Steps 2 and 3 were performed again, and the first and second progressions were combined. Clusters were selected with repetitions. 5) Steps 2-4 were repeated until the length of the progression reached 255.6) Members of the progression were multiplied by an arbitrary constant value ( 2 pixels/video frame $=7.2 \mathrm{~mm} / \mathrm{s}$ ). 7) The generation of the progressions was repeated 28 times for each data set. 


\section{Acknowledgements}

4 We are grateful to Drs. Hitoshi Miyakawa (Utsunomiya Univ.) and Chizue Hiruta (Hokkaido Univ.)

5 for their helpful comments on this manuscript, to Dr. Kei-ichi Okunuki (Nagoya Univ.) for helpful

6 advice on the GIS method, to Dr. Hiroshi Koyama for helpful advice on the random walk models,

7 and to Ms. Mie Watanabe for her technical assistance in preparing the manuscript.

\section{$9 \quad$ Competing interests}

10 The authors declare no conflicts of interest.

\section{$12 \quad$ Funding}

13 The Ministry of Education, Culture, Sports, Science, and Technology of Japan supported this work.

\section{References}

17 Banta, A. M., Brown, L. A. (1929). Control of sex in Cladocera. II. The unstable nature of the excretory products involved in male production. Physiol. Zool. 2, 93-98.

19

20 Bartumeus, F., Catalan, J., Viswanathan, G. M., Raposo, E. P., da Luz, M. G. E. (2008). The

21 influence of turning angles on the success of non-oriented animal searches. J. Theor. Biol. 252, $43-55$. 
1 Bartumeus, F., Peters, F., Pueyo, S., Marrasé, C., Catalan, J. (2003). Helical lévy walks $\square$ : Adjusting

2 searching statistics to resource availability in microzooplankton. Proc. Natl. Acad. Sci. U. S. A. 100,

$3 \quad 12771-12775$.

4

5 Beaver, J. R., Renicker, T. R., Tausz, C. E., Young, J. L., Thomason, J. C., Wolf, Z. L., Russell, A.

6 L., Cherry, M. A., Scotese, K. C., Koenig, D. T. (2018). Winter swarming behavior by the exotic

7 cladoceran Daphnia lumholtzi Sars, 1885 in a Kentucky (USA) reservoir. Bioinvasions Rec. 7,

$8 \quad 43-50$.

9

10 Bianco, G., Ekvall, M. T., Bäckman, J., Hansson, L.-A. (2013). Plankton 3D tracking: the

11 importance of camera calibration in stereo computer vision systems. Limnol. Oceanogr.: Methods

$12 \quad \mathbf{1 1}, 278-286$.

13

14 Bownik, A., Pawlik-Skowońska, B. (2019). Early indicators of behavioral and physiological

15 disturbances in Daphnia magna (Cladocera) induced by cyanobacterial neurotoxin anatoxin-a. Sci.

16 Total Env. 695, 133913.

17

18 Bownik, A., Jasieczek, M., Kosztowny, E. (2020). Ketoprofen affects swimming behavior and

19 impairs physiological endpoints of Daphnia magna. Sci. Total Env. 725, 138312.

20

21 Boxshall, G. A., Defaye, D. (2008). Global diversity of copepods (Crustacea: Copepoda) in

22 freshwater. Hydrobiologia 595, 195-207.

23 
1 Brewer, M. C. (1998). Mating behaviours of Daphnia pulicaria, a cyclic parthenogen: comparisons

2 with copepods. Phil. Trans. Roy. Soc. B: Biol Sci. 353, 681-689.

3

4 Buskey, E. J. (1984). Swimming pattern as an indicator of the roles of copepod sensory system in the

$5 \quad$ recognition of food. Mar. Biol. 79, 165-175.

6

7 Censi, A., Straw, A. D., Sayaman, R. W., Murray, R. M., Dickinson, M. H. (2013). Discriminating

8 external and internal causes for heading changes in freely flying Drosophila. PLoS Comput. Biol. 9,

$9 \quad \mathrm{e} 1002891$.

10

11 Codling, E. A., Plank, J. M., Benhamou, S. (2008). Random walk models in biology. J. R. Soc.

$12 \quad$ Interface 5, 813-834.

13

14 Dodson, S. (1988). The ecological role of chemical stimuli for the zooplankton: Predator-avoidance

15 behavior in Daphnia. Limnol. Oceanogr. 33, 1431-1439.

17 Ebert, D. (2005). Ecology, Epidemiology and Evolution of Parasitism in Daphnia. Bethesda (MD):

18 National Library of Medicine (US), National Center for Biotechnology Information.

20 Felice, B. D., Sabatini, V., Antenucci, S., Gattoni, G., Santo, N., Bacchetta, R., Ortenzi, M. A.,

21 Parolini, M. (2019). Polystyrene microplastics ingestion induced behavioral effects to the cladoceran

22 Daphnia magna. Chemosphere 231, 423-431. 
1 Fortmann-Roe, S., Starfield, R., Getz, W. M. (2012). Contingent kernel density estimation. PLoS

ONE 7, e30549.

3

4 Garcia, R., Moss, F., Nihongi, A., Strickler, J. R., Göller, S., Erdmann, U., Schimansky-Geier, L.,

5 Sokolov, I. M. (2007). Optimal foraging by zooplankton within patches: the case of Daphnia. Math.

6 Biosci. 207, 165-188.

8 Grünbaum, D. (2000). Advection-diffusion equations for internal state-mediated random walks.

$9 \quad$ SIAM J. Appl. Math. 61, 43-73.

10

11 Haury, L., Weihs, D. (1976). Energetically efficient swimming behavior of negatively buoyant

12 zooplankton. Limnol. Oceanogr. 21, 797-803.

14 Hobæk, A., Larsson, P. (1990). Sex determination in Daphnia magna. Ecology 71, 2255-2268.

Hen, I., Sakov, A., Kafkafi, N., Golani, I., Benjamini, Y. (2004). The dynamics of spatial behavior:

how can robust smoothing techniques help? J. Neurosci. Methods 133, 161-172.

18

Jarnagin, S. T., Swan, B. K., Kerfoot, W. C. (2000). Fish as vectors in the dispersal of Bythotrephes 
1 Kiørboe, T., Bagøien, E. (2005). Motility patterns and mate encounter rates in planktonic copepods.

2 Limnol. Oceanogr. 50, 1999-2007.

3

4 Kleiven, O. T., Larsson, P., Hobæk, A. (1992). Sexual reproduction in Daphnia magna requires three

$5 \quad$ stimuli. Oikos 65, 197-206.

6

7 Kotov, A., Forró, L., Korovchinsky, N. M., Petrusek, A. (2012). "Crustacea-Cladocera checkList"

8 World checklist of freshwater Cladocera species. Belgian Biodiversity Platform.

10 Martins, J., Oliva, T. L., Vasconcelos, V. (2007). Assays with Daphnia magna and Dario rerio as

11 alert systems in aquatic toxicology. Environ. Int. 33, 414-425.

13 Matsunaga, W., Watanabe, E. (2012). Visual motion with pink noise induces predation behaviour.

14 Sci. Rep. 2, 219.

16 Mitchell, S. E. (2001). Intersex and male development in Daphnia magna. Hydrobiologia 442,

$17 \quad 145-156$.

18

19 Nakaoka, Y., Imaji, T., Hara, M., Hashimoto, N. (2009). Spontaneous fluctuation of the resting

20 membrane potential in Paramecium: amplification caused by intracellular $\mathrm{Ca}^{2+} . J$. Exp. Biol. 212,

$21270-276$. 
1 Noss, C., Dabrunz, A., Rosenfeldt, R. R., Lorke, A., Schulz, R. (2013). Three-dimentional analysis

2 of the swimming behavior of Daphnia magna exposed to nanosized titanium dioxide. PLoS ONE 8 ,

$3 \mathrm{e} 80960$.

4

5 Oda, S., Tatarazako, N., Dorgerlon, M., Johnson, R. D., Usk, K. O., Leverett, D., Marchini, S.,

6 Nakari, T., Williams, T., Iguchi, T. (2007). Strain difference in sensitivity to 3,4-dichloroaniline and

7 insect growth regulator, fenoxycarb, in Daphnia magna. Ecotoxicol. Env. Safety 67, 399-405.

9 Oda, S., Tatarazako, N., Watanabe, H., Morita, M., Iguchi, T. (2006). Genetic differences in the

10 production of male neonates in Daphnia magna exposed to juvenile hormone analogs. Chemosphere

$1163,1477-1484$.

12

13 OECD. (2012). Guidelines for testing of chemicals. In Daphnia magna reproduction test. OECD:

14 Paris.

16 Ohkubo, J., Yoshida, K., Iino, Y., Masuda, N. (2010). Long-tail behavior in locomotion of

Caenorhabditis elegans. J. Theor. Biol. 267, 213-222.

18

19 Øien, A. H. (2004). Daphnicle dynamics based on kinetic theory: An analogue-modelling of

20 swarming and behavior of Daphnia. Bull. Math. Biol. 66, 1-46.

23 Edition. Springer (New York). 
2 Olmstead, A. W., LeBlanc, G. A. (2000). Effects of endocrine-active chemicals on the development

3 of sex characteristics of Daphnia magna. Environ. Toxicol. Chem. 19, 2107-2113.

4

$5 \quad$ Postlethwaite, C. M., Dennis, T. E. (2013). Effects of temporal resolution on an inferential model of

$6 \quad$ animal movement. PLOS ONE 8, e57640.

8 Schimansky-Geier, L., Erdmann, E., Komin, N. (2005). Advantages of hopping on a zig-zag course.

$9 \quad$ Physica. A 351, 51-59.

11 Seuront, L., Strutton, P. G. (2003). Handbook of Scaling Methods in Aquatic Ecology: Measurement, 12 Analysis, Simulation. CRC Press (Boca Raton, FL).

14 Seuront, L., Hwang, J.-S., Tseng, L.-C., Schmitt, F. G., Souissi, S., Wong, C.-K. (2004a). Individual

15 variability in the swimming behavior of the sub-tropical copepod Oncaea venusta (Copepoda:

16 Poecilostomatoida). Mar. Ecol. Prog. Series 283, 199-217.

18 Seuront, L., Schmitt, F. G., Brewer, M. C., Strickler, J. R., Souissi, S. (2004b). From random walk to

19 multifractal random walk in zooplankton swimming behavior. Zool. Stud. 43, 498-510.

21 Silverman, B. W. (1986). Density Estimation for Statistics and Data Analysis. Chapman and Hall

22 (London). 
1 Smith, G. (1915). The life-cycle of Cladocera, with remarks on the physiology of growth and

2 reproduction in crustacea. Proc. R. Soc. London Ser. B: Biol. Sci. 88, 418-435.

3

4 Srivastava, N., Clark, D. A., Samuel, A. D. T. (2009). Temporal analysis of stochastic turning

behavior of swimming C. elegans. J. Neurophysiol. 102, 1172-1179.

7 Tatarazako, N., Oda, S., Watanabe, H., Morita, M., Iguchi, T. (2003). Juvenile hormone agonists

8 affect the occurrence of male Daphnia. Chemosphere 53, 827-833.

9

10 Toyota, K., Cuenca M. C., Dhandapani, V., Suppa, A., Rossi, V., Colbourne, J. K., Orsini, L. (2019).

11 Transgenerational response to early spring warming in Daphnia. Sci. Rep. 9, 4449.

13 Toyota, K., Miyakawa, H., Hiruta, C., Furuta, K., Ogino, Y., Shinoda, T., Tatarazako, N., Miyagawa,

14 S., Shaw, J. R., Iguchi, T. (2015). Methyl farnesoate synthesis is necessary for the environmental sex

15 determination in the water flea Daphnia pulex. J. Insect Physiol. 80, 22-30.

17 Toyota, K., Sato, T., Iguchi, T. and Ohira, T. (2021). Methyl farnesoate regulatory mechanisms

18 underlying photoperiod-dependent sex determination in the freshwater crustacean Daphnia magna. J.

19 Appl. Toxicol. 41 (2), 216-223. 
1 Visser, A. W., Thygesen, U. H. (2003). Random motility of plankton: diffusive and aggregative

2 contributions. J. Plankton Res. 25, 1157-1168.

4 Winsor, G. L., Innes, D. J. (2002). Sexual reproduction in Daphnia pulex (Crustacea: Cladocera):

5 observations on male mating behavior and avoidance of inbreeding. Freshwater Biol. 47, 441-450.

7 Worton, B. J. (2002). Kernel methods for estimating the utilization distribution in home-range

8 studies. Ecology 70, 164-168.

9

10

11 


\section{$1 \quad$ Figure legends}

2 Figure 1. D. magna.

3 Sexually mature female (left) and male (right) D. magna (lateral view). Scale bar, $1 \mathrm{~mm}$.

$5 \quad$ Figure 2. Overview of swimming trajectories.

6 Time series plot of female (A) and male (B) D. magna. In total, 7,196 coordinates (240 sets, 257

7 consecutive coordinates per individual, $n=28$ ) of the calculated centre of mass of $D$. magna were

8 plotted along the vertical and horizontal axes. Consecutive coordinates were normalised to the given

9 halfway point (the $129^{\text {th }}$ coordinate), which was set as vertical coordinate 50 and horizontal

10 coordinate 50. Each plot was annotated by arbitrary symbols with different colours (blue, red, green,

11 orange, violet or yellow). Trajectory graphs are represented as probability density plots for females

12 (C) and males (D). Kernel density estimation was performed using a quartic kernel function with a

13 bandwidth of $12 \mathrm{~mm}$. The two-dimensional density map was visualised using terra colours. Scale bar,

$1410 \mathrm{~mm}$.

Figure 3. Mean squared displacement of D. magna.

17 The mean squared displacements (MSDs) of female (red) and male (blue) D. magna are plotted

18 along the vertical (top) and horizontal (bottom) axes (logarithmic scales, $n=28$ ). Best-fit lines using

19 a power-law approximation are shown in black. The power-law exponent $(\alpha)$ and least mean square

$20 \quad\left(R^{2}\right)$ are shown in the plots.

Figure 4. Autocorrelation function of D. magna.

23 Average normalised autocorrelation functions of female (top) and male (bottom) D. magna are

24 plotted along the vertical (left) and horizontal (right) axes $(n=28)$. 
2 Figure 5. Mean squared displacement of model MC1.

3 The mean squared displacements (MSDs) of females (left) and males (right) of model MC1 are

4 plotted along the vertical (top) and horizontal (bottom) axes (logarithmic scales, $n=28$ ). Best-fit

$5 \quad$ lines using a power-law approximation are shown in black. The power-law exponent $(\alpha)$ and least

6 mean square $\left(R^{2}\right)$ are shown in the graphs. The data shown represent the means $\pm \mathrm{SEM}$.

\section{Figure 6. Frequency distribution of move-step length.}

9 The move-step lengths derived from 7,168 velocities are plotted in linear (left) and single

10 logarithmic (right, log-linear model) scale plots. The data for females (red) are superimposed on the

11 data for males (blue). Bin width, $0.12 \mathrm{~mm}$. Best-fit lines using an exponent function are shown in

12 black. The exponent function and least mean square are shown in the plots.

\section{$14 \quad$ Figure 7. SCIS analysis.}

15 (A) Brief overview of the definition of the dominant and recessive directions and durations with an identical sign. The major direction is defined as dominant and is indicated by the plus sign (refer to 
$1 \quad$ Figure 8. Mean squared displacement of model MC3.

2 The mean squared displacements for females (red) and males (blue) based on model MC3, which

3 was derived from the duration with an identical sign, are plotted along the vertical (top) and

4 horizontal (bottom) axes (logarithmic scales, $\mathrm{n}=28)$. A constant arbitrary speed $(7.2 \mathrm{~mm} / \mathrm{s}$ ) was

5 used for this simulation. Best-fit lines using a power-law approximation are shown in black. The

6 power-law exponent $(\alpha)$ and least mean square $\left(R^{2}\right)$ are shown in the plots.

8 Figure 9. Net-to-gross displacement ratios of $D$. magna and two MC models.

9 (A) Brief overview of the definition of the net-to-gross displacement ratios (NGDRs). Net

10 displacement (ND) is the straight line distance between the initial and final locations, and gross

11 displacement (GD) is the sum of the distance Di. (B) NGDRs observed in the raw data derived from

12 D. magna are shown relative to those from $\mathrm{MC} 1$ and $\mathrm{MC} 3$. The term ' $\mathrm{fv}$ ' indicates the vertical

13 direction of females, 'fh' indicates the horizontal direction of females, 'mv' indicates the vertical

14 direction of males and ' $m$ ' indicates the horizontal direction of males.

Supplemental Figure 1. Frequency distribution of velocity.

17 A frequency histogram of the velocities derived from 7,168 vectors derived from female or male

18 zooplankton. The velocity was calculated separately in the horizontal and vertical axes. Bin width $=$

$191 \mathrm{pixel} /$ video frame $(0.12 \mathrm{~mm} / 33.3 \mathrm{~ms})$.

20

21 Supplemental Movie 1. Female D. magna.

22 An example of a female D. magna. Width of the movie is 640 pixels $(76.8 \mathrm{~mm})$, and height is 480

23 pixels $(57.6 \mathrm{~mm})$. Frame rate is $30 \mathrm{fps}$. 
bioRxiv preprint doi: https://doi.org/10.1101/2021.01.21.427564; this version posted January 21, 2021. The copyright holder for this preprint (which was not certified by peer review) is the author/funder, who has granted bioRxiv a license to display the preprint in perpetuity. It is made available under aCC-BY-NC-ND 4.0 International license.

\section{Supplemental Movie 2. Male D. magna.}

2 An example of a male $D$. magna. Width of the movie is 640 pixels $(76.8 \mathrm{~mm})$, and height is 480

3 pixels $(57.6 \mathrm{~mm})$. Frame rate is $30 \mathrm{fps}$. 
bioRxiv preprint doi: https://doi.org/10.1101/2021.01.21.427564; this version posted January 21, 2021. The copyright holder for this preprint (which was not certified by peer review) is the author/funder, who has granted bioRxiv a license to display the preprint in perpetuity. It is made available under aCC-BY-NC-ND 4.0 International license.
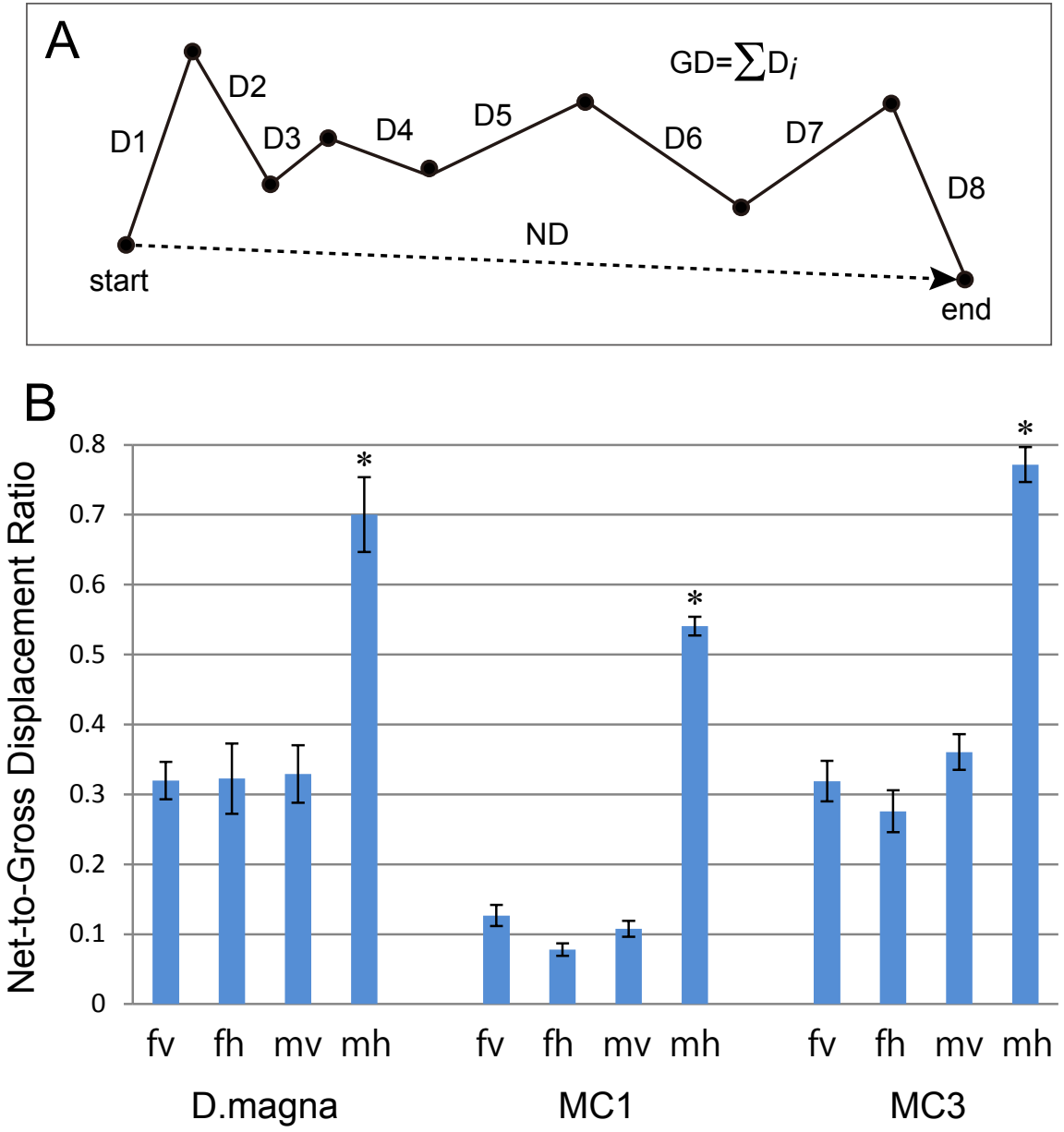
bioRxiv preprint doi: https://doi.org/10.1101/2021.01.21.427564; this version posted January 21, 2021. The copyright holder for this preprint (which was not certified by peer review) is the author/funder, who has granted bioRxiv a license to display the preprint in perpetuity. It is made available under aCC-BY-NC-ND 4.0 International license.

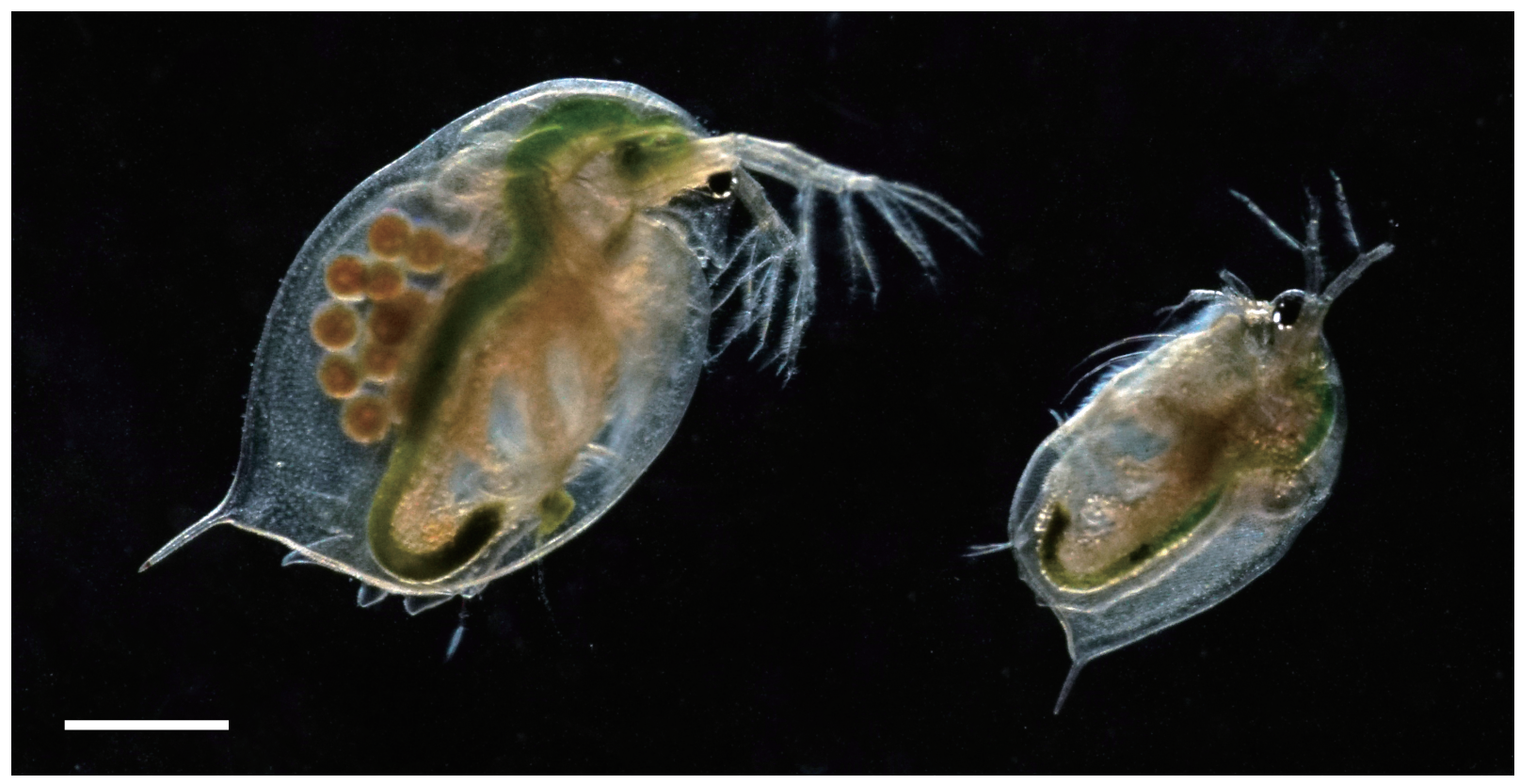


bioRxiv preprint doi: https://doi.org/10.1101/2021.01.21.427564; this version posted January 21, 2021. The copyright holder for this preprint (which was not certified by peer review) is the author/funder, who has granted bioRxiv a license to display the preprint in perpetuity. It is made available under aCC-BY-NC-ND 4.0 International license.

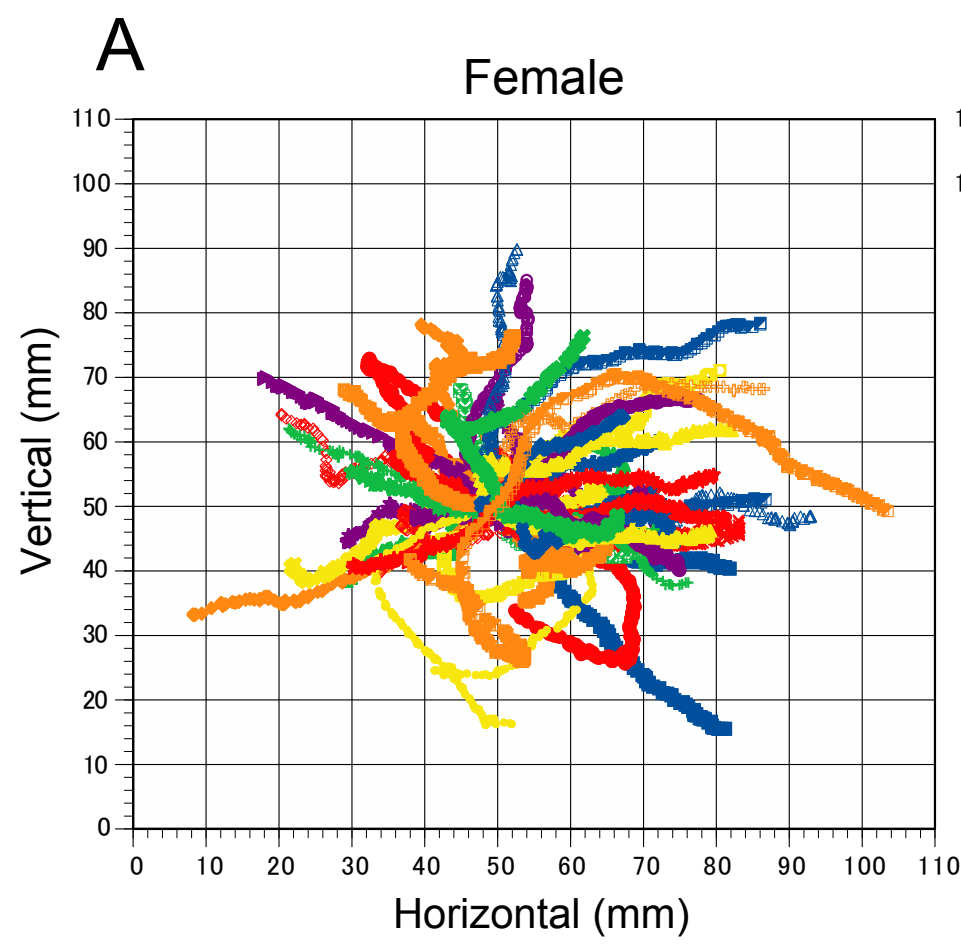

C

Female

\section{B}

Male

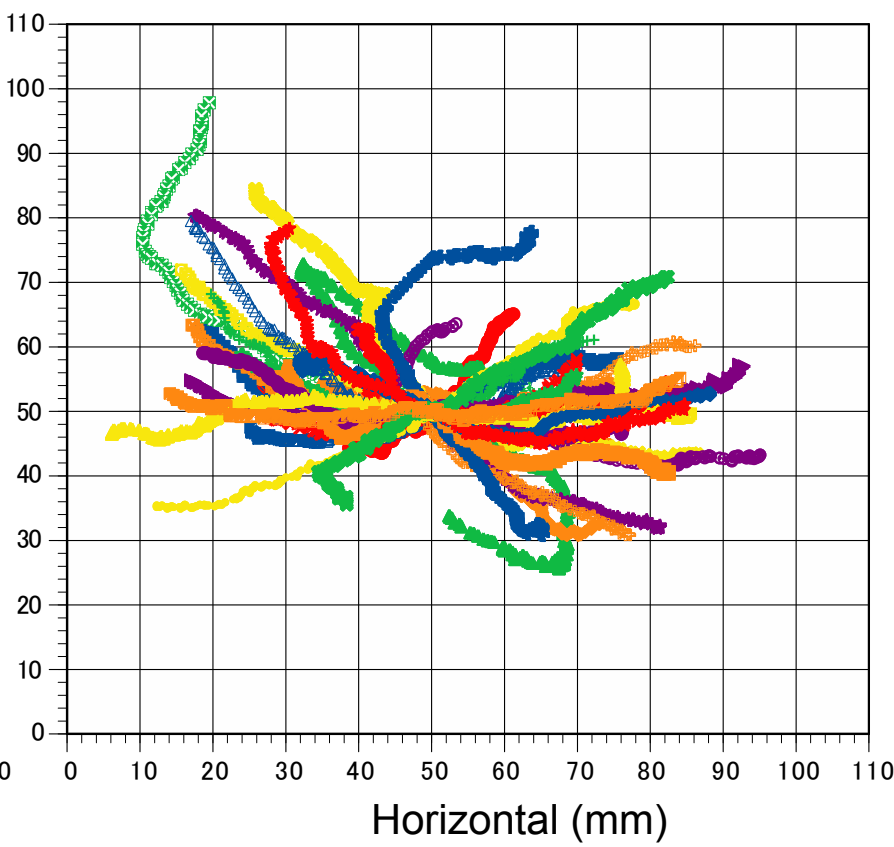

D

Male
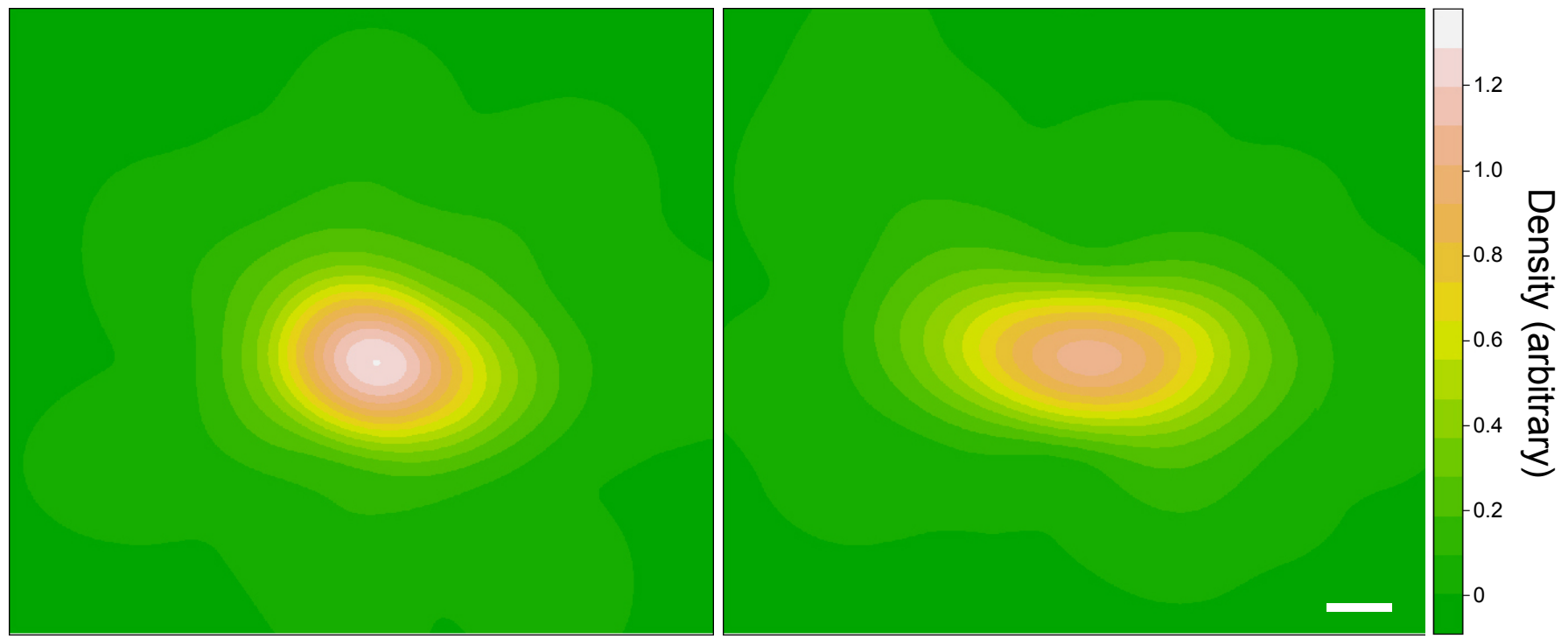
bioRxiv preprint doi: https://doi.org/10.1101/2021.01.21.427564; this version posted January 21, 2021. The copyright holder for this preprint (which was not certified by peer review) is the author/funder, who has granted bioRxiv a license to display the preprint in perpetuity. It is made available under aCC-BY-NC-ND 4.0 International license.

D.magna (Female \& Male)

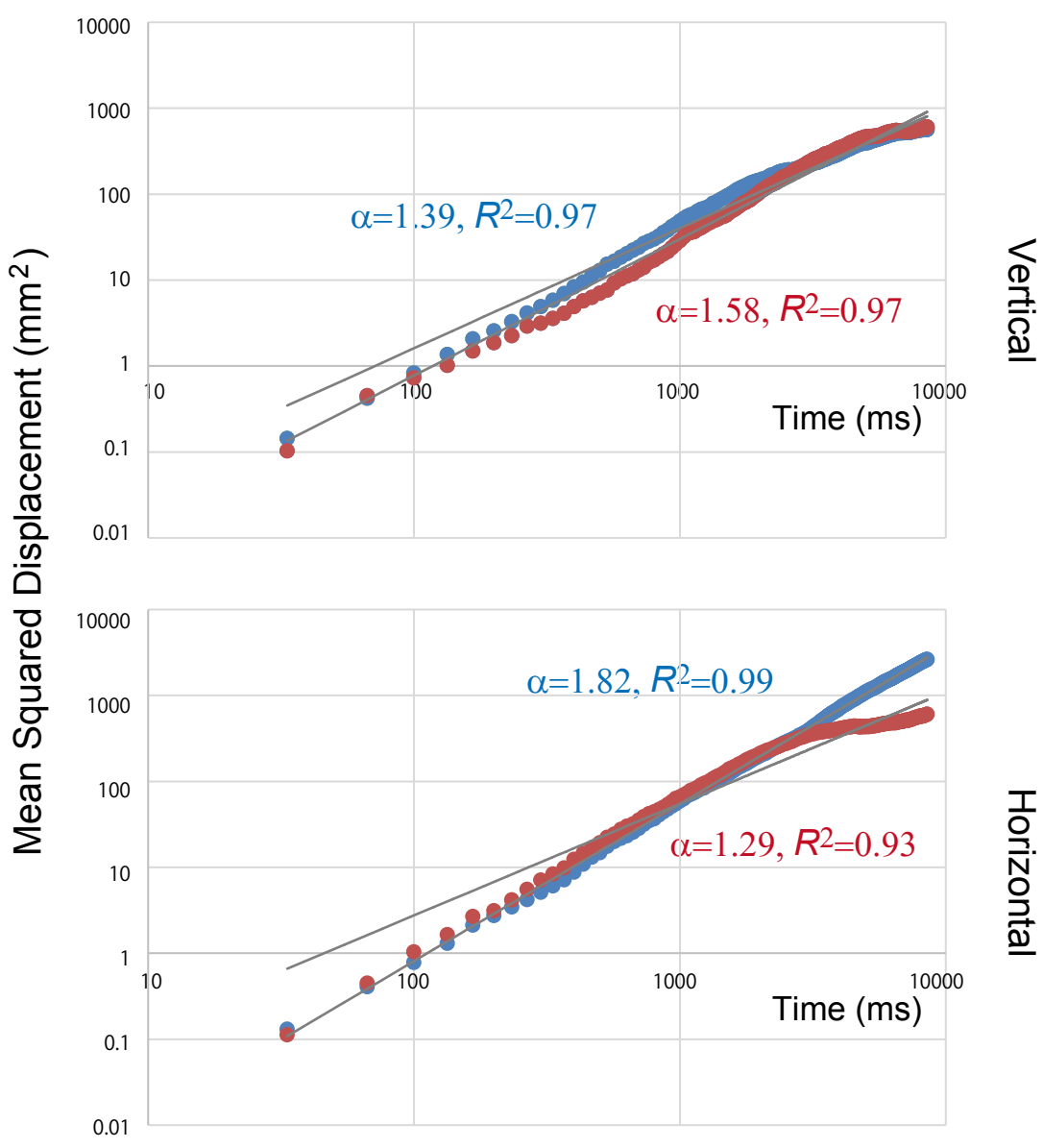


bioRxiv preprint doi: https://doi.org/10.1101/2021.01.21.427564; this version posted January 21, 2021. The copyright holder for this preprint (which was not certified by peer review) is the author/funder, who has granted bioRxiv a license to display the preprint in perpetuity. It is made available under aCC-BY-NC-ND 4.0 International license.
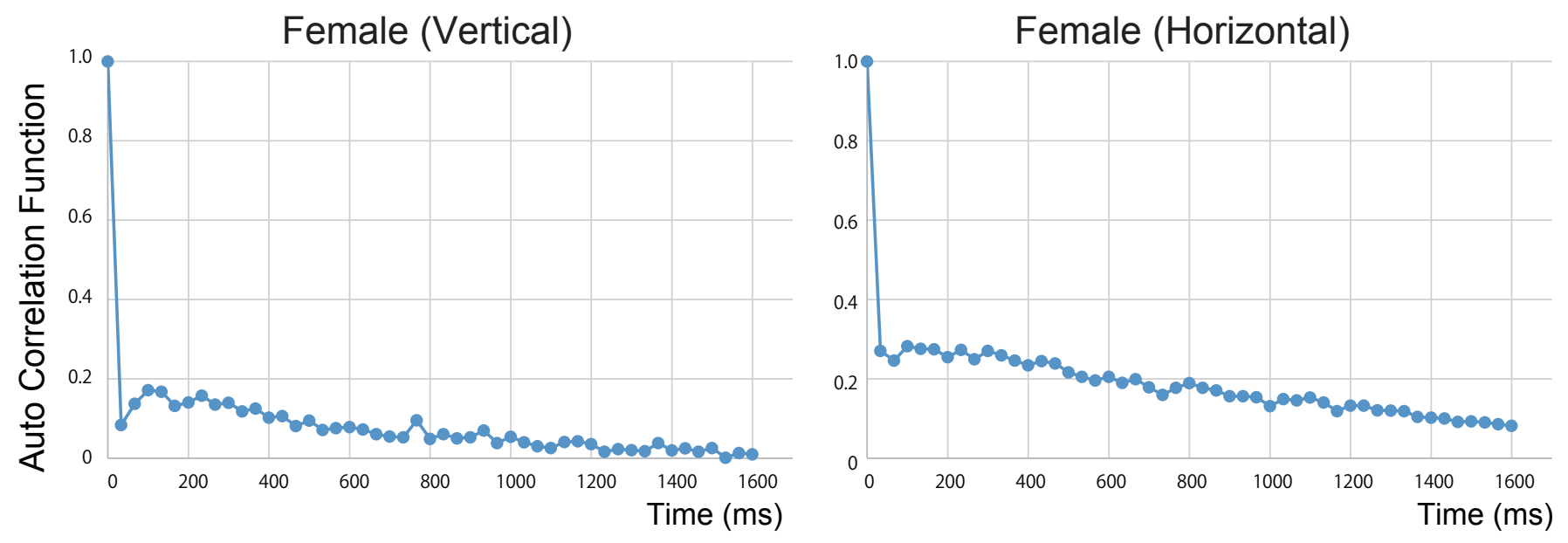

Male (Vertical)
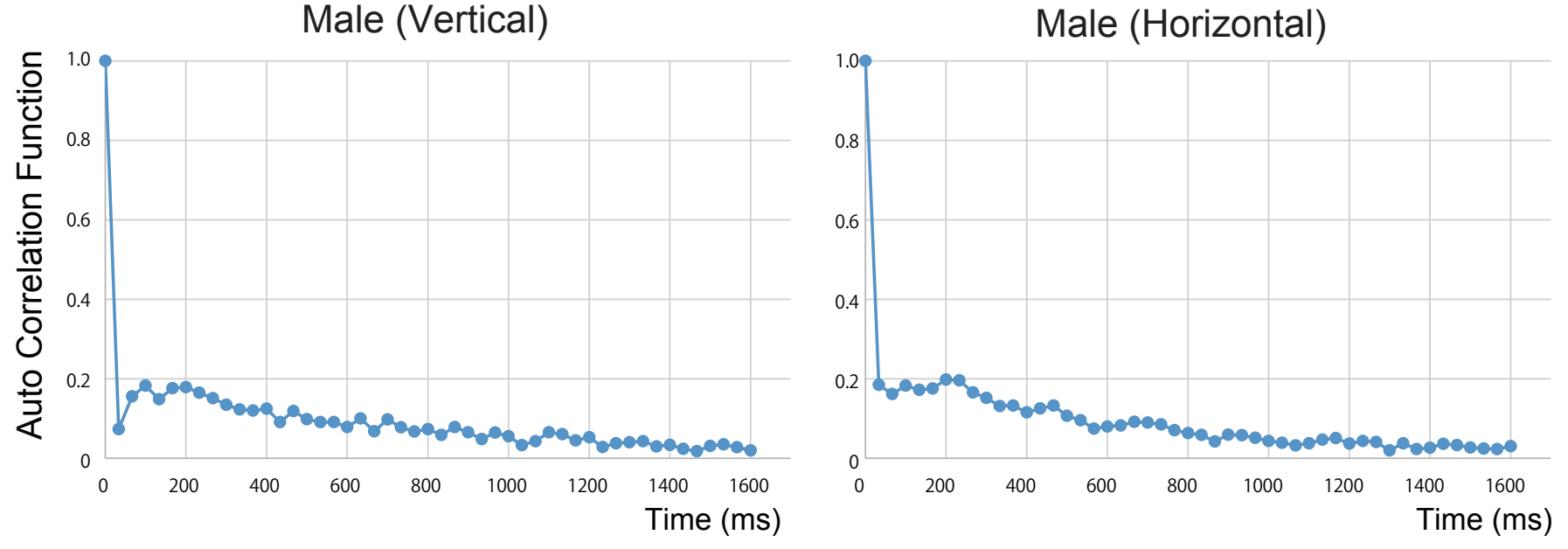
bioRxiv preprint doi: https://doi.org/10.1101/2021.01.21.427564; this version posted January 21, 2021. The copyright holder for this preprint (which was not certified by peer review) is the author/funder, who has granted bioRxiv a license to display the preprint in perpetuity. It is made available under aCC-BY-NC-ND 4.0 International license.

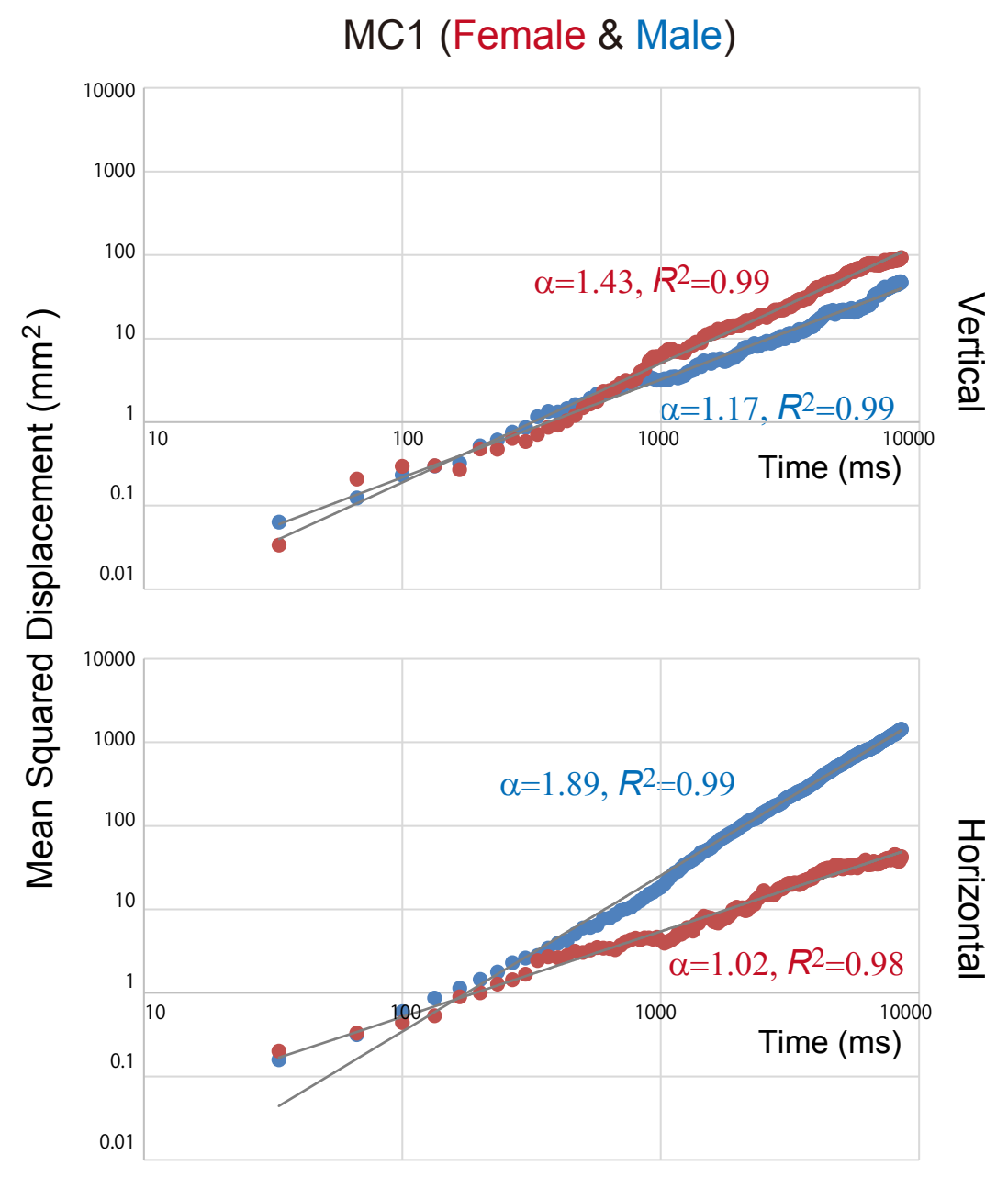


bioRxiv preprint doi: https://doi.org/10.1101/2021.01.21.427564; this version posted January 21, 2021. The copyright holder for this preprint (which was not certified by peer review) is the author/funder, who has granted bioRxiv a license to display the preprint in perpetuity. It is made available under aCC-BY-NC-ND 4.0 International license.
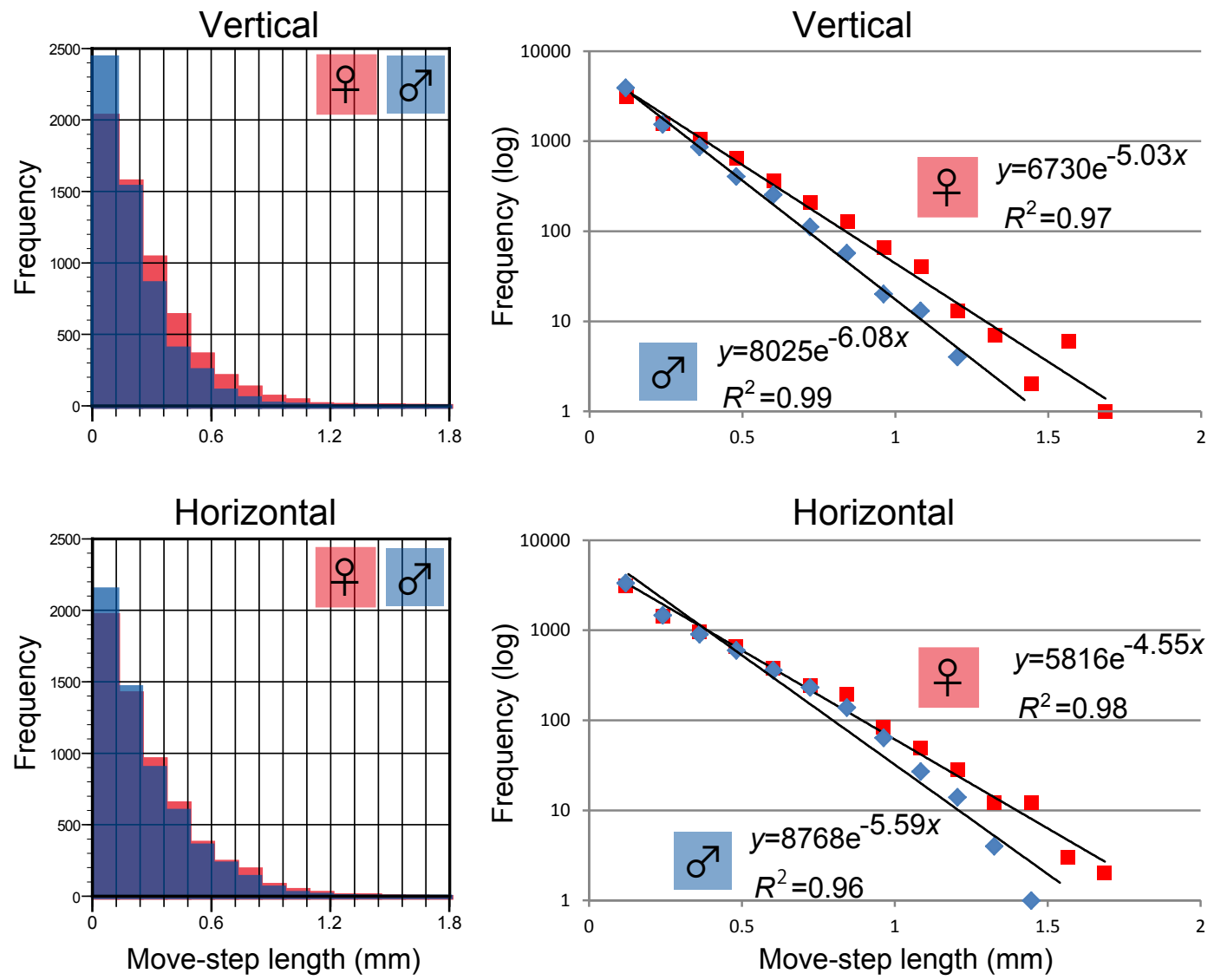
bioRxiv preprint doi: https://doi.org/10.1101/2021.01.21.427564; this version posted January 21, 2021. The copyright holder for this preprint (which was not/Aertified byDPefferfiew) is the author/funder, who has granted bioRxiv a license to display the preprint in perpetuity. It is made of moving available under aCC-BY-NC-ND 4.0 International license.
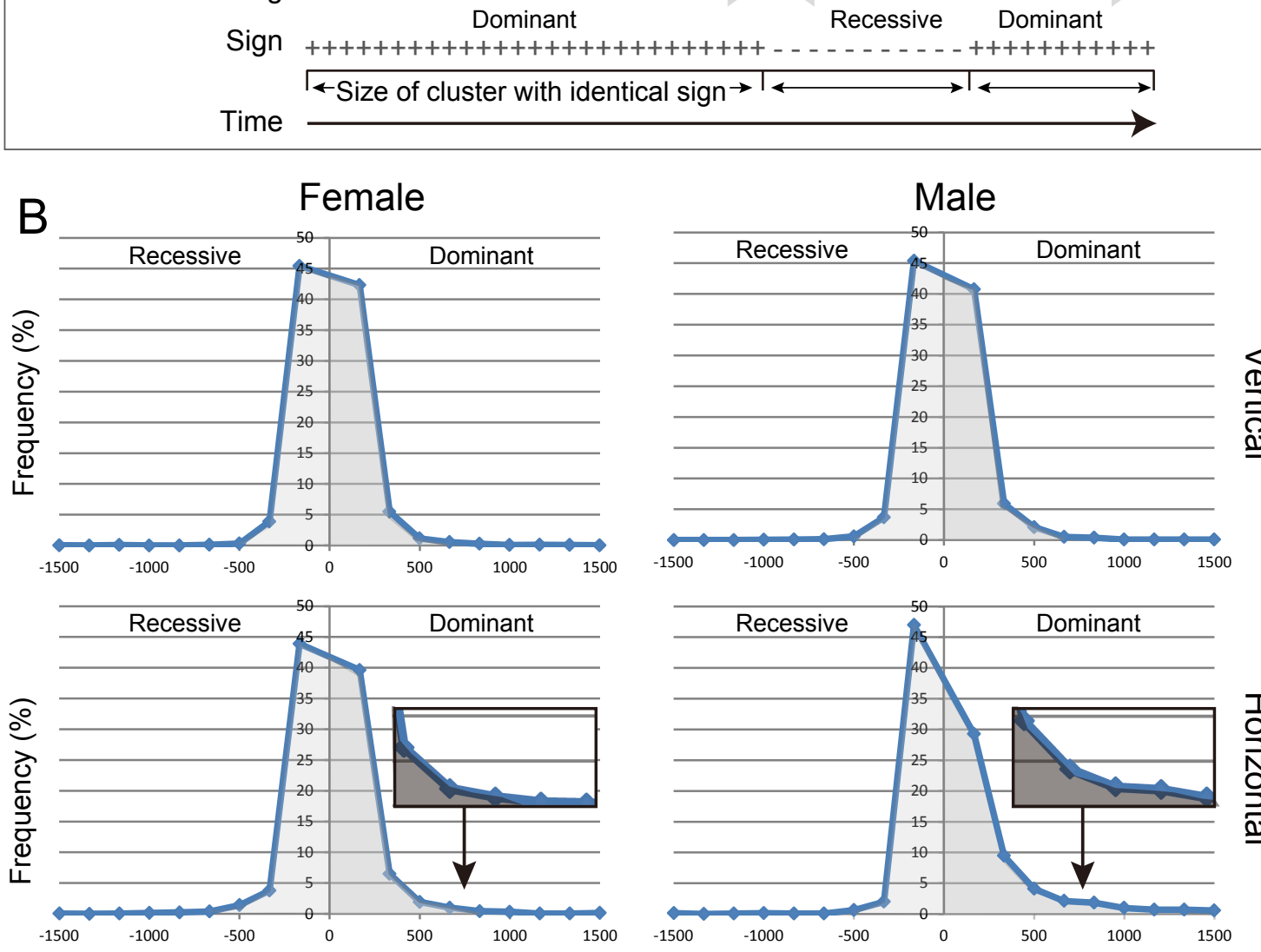

Size of cluster with identical sign (msec)

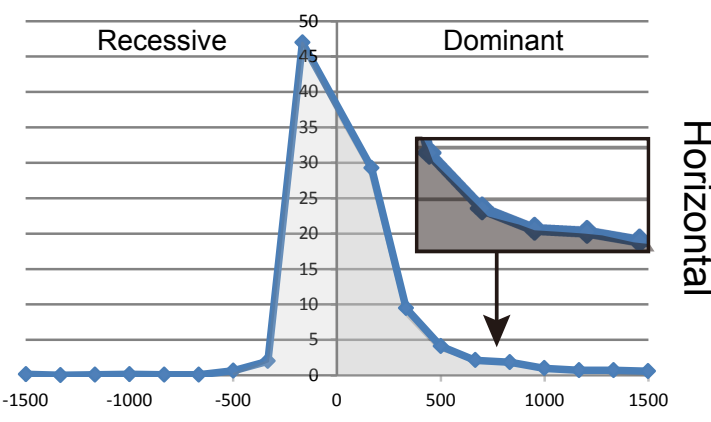

Size of cluster with identical sign (msec)

C

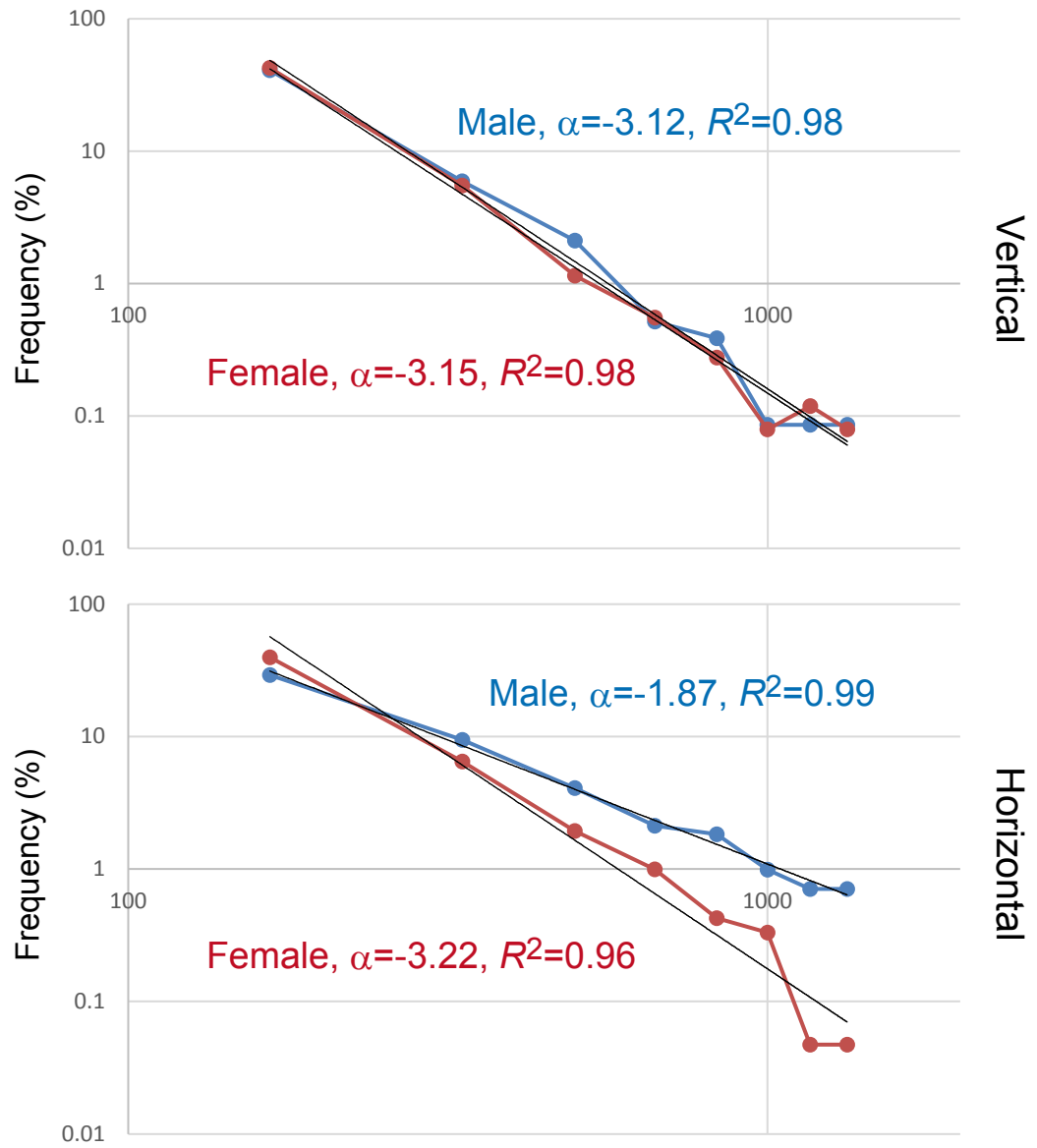

Size of cluster with identical sign (msec) 
bioRxiv preprint doi: https://doi.org/10.1101/2021.01.21.427564; this version posted January 21, 2021. The copyright holder for this preprint (which was not certified by peer review) is the author/funder, who has granted bioRxiv a license to display the preprint in perpetuity. It is made available under aCC-BY-NC-ND 4.0 International license.

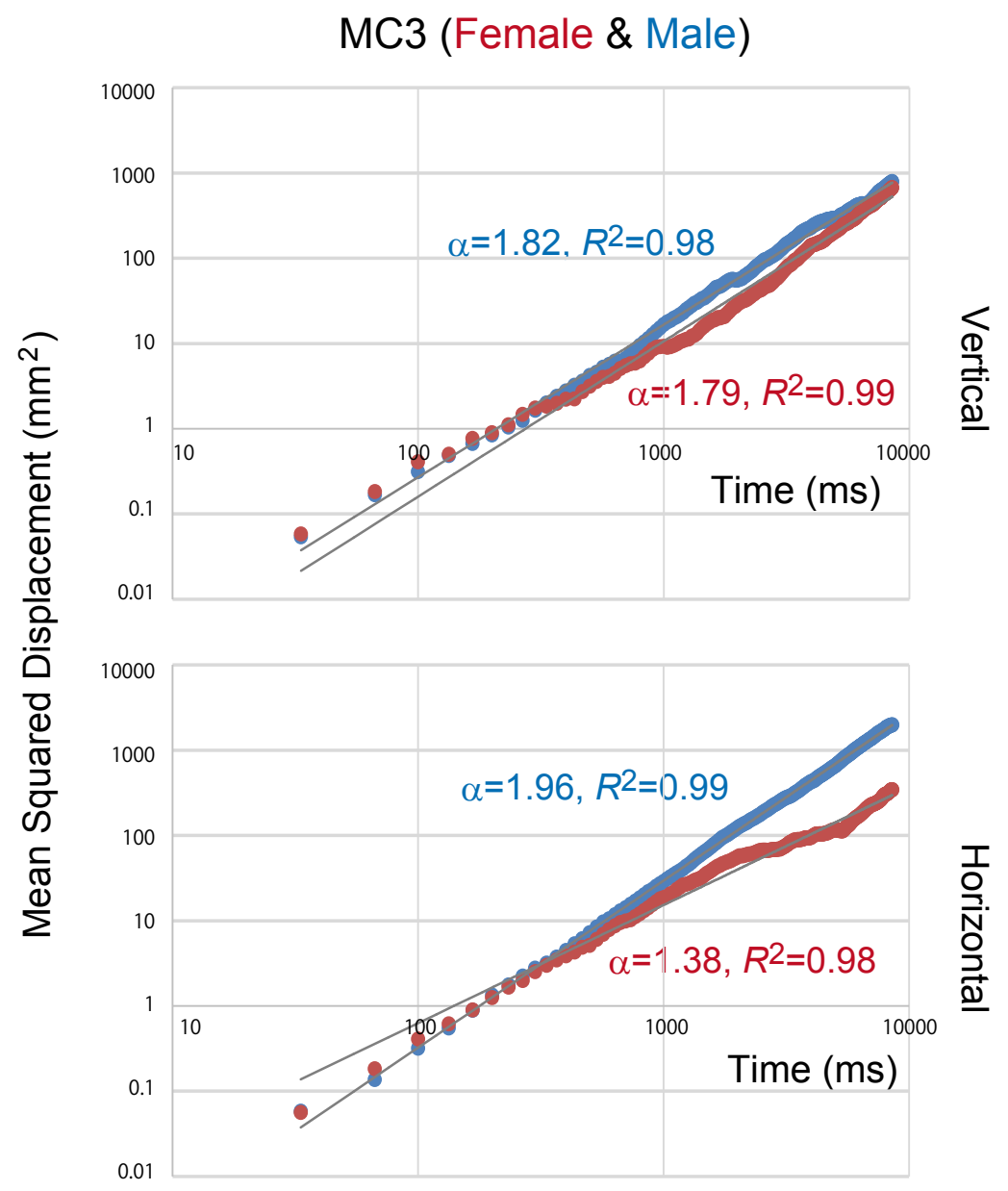

